\title{
Los Épera Siapidara en Ecuador. proceso de visibilización
}

Eulalia Carrasco A. ${ }^{1}$

RESUMEN

El presente artículo tiene como finalidad, PRESENTAR al PUEblo Épera Siapidara de Ecuador, EN EL PRoceso DE “VISIBILIZACIÓN” (CARRASCO, 2010: 5) Y FORTALECIMIENTO DE SU IDENTIDAD, A TRAVÉS FUNDAMENTALMENTE DEL ACCESO AL TERRITORIO Y DE LA REVALORIZACIÓN DE SU ESPIRITUALIDAD EXPRESADA EN LAS RELACIONES COMUNITARIAS, EN LA RELACIÓN CON LA TIERRA Y EN LOS RITUALES ANCESTRALES, CON UNA RED DE SOLIDARIDAD DE ALIADOS Y AMIGOS QUE APOYAN ESTE CAMINAR.

A fines de LA DÉCADA DE LOS 90, SE EMPEZÓ A ESCUCHAR EL NOMBRE DE UN PUEBLO INDÍGENA, DESCONOCIDO EN EL ÁMBITO NACIONAL, HASTA ENTONCES: LOS ÉPERA. EN LA CONAIE NO TENÍAN MAYOR INFORMACIÓN, SÓLO SABÍAN QUE ESTABA LOCALIZADO EN LA PROVINCIA DE ESMERALDAS EN UNA SITUACIÓN DE EXTREMA VULNERABILIDAD. EN ESMERALDAS EN LA DiRECCIÓN de EdUCACIÓN BILINGÜE, EL FUNCIONARIO ENCARGADO ME INFORMÓ QUE EL PROFESOR CHACHI DEL BARRIO CAYAPA EN BORBÓN TIENE ALUMNOS ÉPERA, NO HAY NINGÚN REGISTRO DE SU LENGUA, NO TIENEN TERRITORIO,

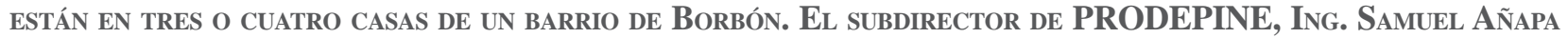
CONOCía QUE había ALGUNAS FAMILIAS DISPERSAS AL NORTE DE LA PROVINCIA DE ESMERALDAS. LOS MIEMBROS DEL Vicariato de Esmeraldas, de la zona norte, en Asamblea Pastoral de octubre de 1999, no conocían tampoco LA EXISTENCIA DEL PUEBLO ÉPERA, AUNQUE HABÍAN OÍDO HABLAR DE LOS “CHOLOS COLOMBIANOS”.

Palabras claves: Épera-Mitos

\section{Abstract}

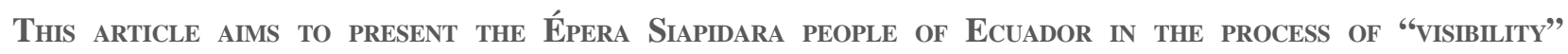
(CARRASCO, 2010: 5) AND STRENGTHENING OF THEIR IDENTITY, MAINLY THROUGH THE ACCESS TO THE TERRITORY AND THE UPGRADING OF THEIR SPIRITUALITY AS EXPRESSED IN THE COMMUNITY RELATIONS, IN THEIR RELATION TO LAND AND ANCESTRAL RITUALS, WITH A SOLIDARITY NETWORK OF ALLIES AND FRIENDS TO SUPPORT THIS WALK. IN THE LATE 90's, THE NAME OF AN INDIGENOUS PEOPLE BEGAN TO SOUND, THE UNKNOWN NATIONALITY UNTIL THEN, THE EPER. THE CONAIE HAD NO SIGNIFICANT INFORMATION, JUST KNEW IT WAS LOCATED IN THE PROVINCE OF ESMERALDAS IN A SITUATION OF EXTREME VULNERABILITY. In ESMERALDAS AT THE BILINGUAL EdUCATION DEPARTMENT, THE OFFICER INFORMED ME THAT THE CHACHI TEACHER OF THE CAYAPA NEIGHBORHOOD IN BOURBON, HAS ÉPERA STUDENTS, THERE IS NO RECORD OF THEIR LANGUAGE, HAVE NO TERRITORY, AND LIVE IN THREE OR FOUR HOUSES IN A NEIGHBORHOOD OF Bourbon . PRODEPINE deputy director, Mr. SAMuel AÑapa KNEW that THere Were SOME Families SCATTERED NORTH OF THE PROVINCE OF EsMERALDAs. THE MEMBERS OF THE ViCARIATE OF EsMERALDAS, IN THE NORTH ZONE, IN

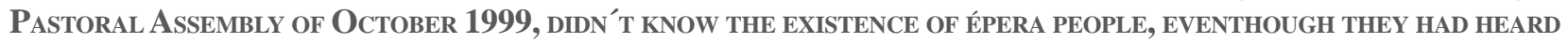
OF THE COLOMBIAN “CHOLOS”.

KEYWORDS: ÉPERA-MYTHS

1 Antropóloga. Este artículo es una síntesis de su libro: Los Epera Siapidara en Ecuador. De la invisibilidad a la visibilidad, Tramaediciones, Quito 2010. 


\section{Quienes son los Épera}

工 1 Pueblo Épera forman parte de los Emberá (Otero, 1952: 107) que habitan el Chocó, -1 que se extiende desde las costas de Panamá y Colombia hasta el norte de Ecuador.

El Pueblo Éperara siapidaara es gente de los ríos, están míticamente ligados al agua. Es el pueblo de la sabiduría chamánica. Esta sabiduría es la que los llevó a relacionarse con los llamados Cayapas, a inicios del siglo pasado (1908), según cita Barrett:

"Hay otras dos etnias, con las que los Cayapas se relacionan: Los llamados por el término ambiguo de „,cholos, al norte, que viven a lo largo del río Saija... este grupo es muy distinto al Cayapa, tanto social como lingüísticamente hablando, pero ejerce alguna influencia sobre todo en las prácticas medicinales...” (Barrett, 1994: 31).

El significado del nombre: "Épera Siapidara”, tiene un mito fundante que da trascendencia al origen del pueblo:

ÉPERA $=$ PERSONA

ÉPERAARA = PUEBLO (plural)

SIA = CAÑA BRAVA

PIDAARA $=$ SON, PERTENECEN

PEDEE $=$ LENGUA

"PUEBLO ORIGINARIO DE LA CAÑA BRAVA"

En Colombia el pueblo Éperara Siapidara está distribuido a lo largo de la Costa del Pacífico sur en treinta y dos comunidades y tiene una población de 7.000 habitantes. Los Éperara Siapidara, hacen parte del grupo indígena conocido como Chocó, el cual presenta la siguiente división lingüística según el antropólogo Mauricio Pardo:

\section{1. la lengua Wounaan}

2. la lengua emberá, la cual presenta las siguientes divisiones:

- Dialecto emberá de Panamá, alto y bajo Atrato.

- Dialecto emberá del noroccidente antioqueño y Córdova.

- Dialecto emberá del alto San Juan: Chamí.

- Dialecto embera del medio Baudó: Catre y Dusa.

- Dialecto embera; costa al sur de Buenaventura, Sia Pedeé.

Por lo anterior, los Épera son reconocidos por la antropología como parte de la gran familia embera. Sin embargo, los Eperara Siapidara presentan una dinámica cultural propia, al igual que una adaptación territorial que se puede interpretar desde su cosmovisión sia (ACIESNAACIESCA-OZBESCAC, 1997).

La presencia de los Éperara Siapidara, conocidos como “cholos colombianos” se intensificó en Esmeraldas, por la violencia que grupos armados en Colombia amenazaban la vida de las familias de este pueblo. Los asentamientos sedentarios en Esmeraldas se dan en la década de los 60 a lo largo de los ríos Cayapas , Onzole, Santiago, Bogotá. En el año de 1999 se identificaron trece asentamientos, generalmente de familias ampliadas en: Esmeraldas- Codesa, Tambillo, La Tola, Garceo, Palma, Capricho, Bella Aurora, Concepción, San Francisco, Las Peñas, Quinindé, Canandé, vivían dispersos y con pocas posibilidades de comunicarse. Eran 54 familias con 294 miembros en total, quienes procedían mayoritariamente del Departamento del Cauca en Colombia, de los ríos Infi, Micay y Saija. 


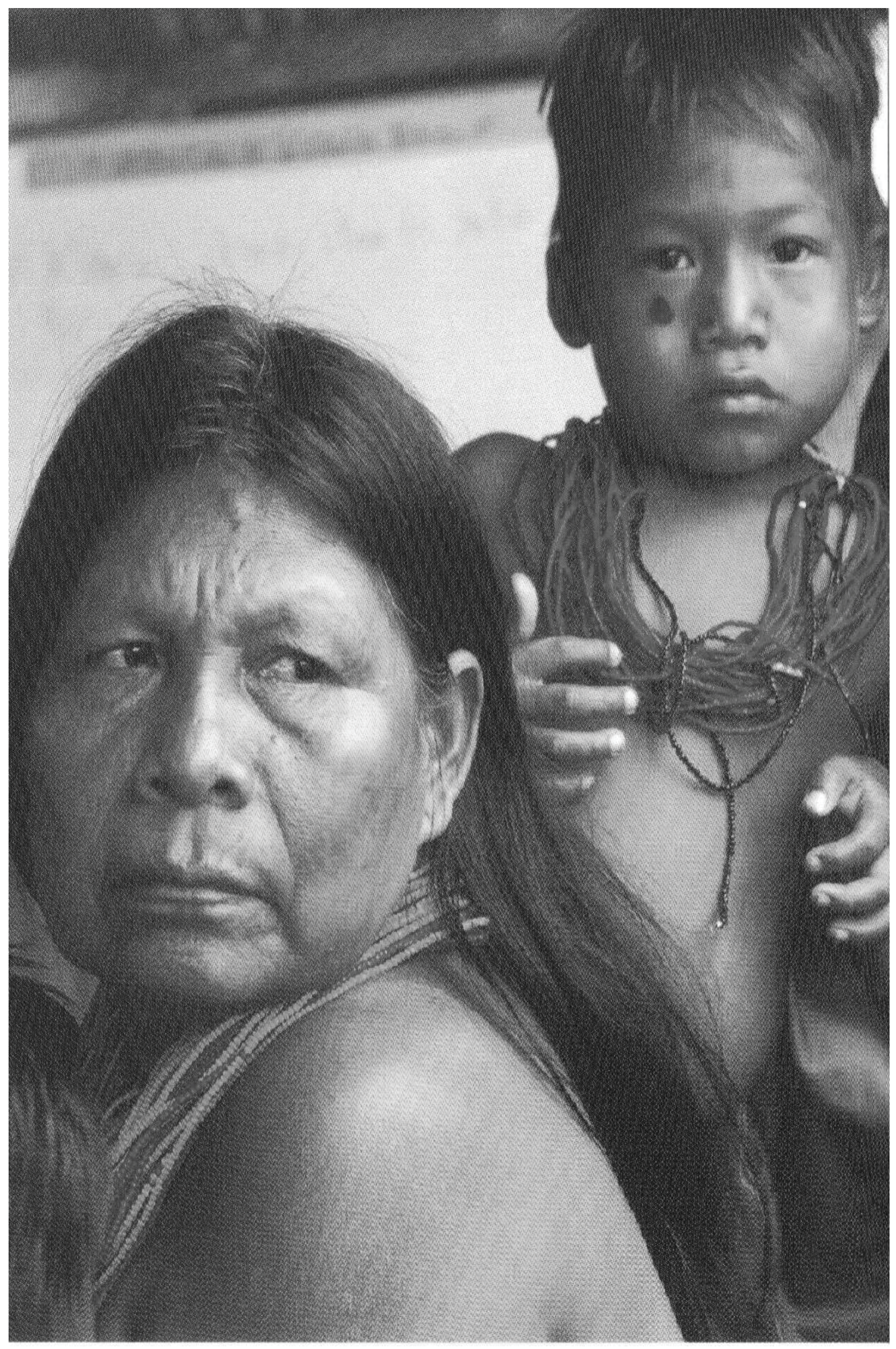




\section{Mito originario de los Eperaara Siapidaara}

El Pueblo Épera lleva sus mitos como bagaje cultural que le da raíces, que lo constituye como pueblo con identidad definida. Entre los más importantes está el de sus orígenes, que lo ancla en la trascendencia y fundamenta sus normas de vida, especialmente la exogamia entre parientes consanguíneos y la endogamia en relación a otros pueblos, además fundamenta la pluriculturalidad y el multilingüismo.

"Según la historia que hemos recibido de los viejos, la creación del pueblo Épera, según lo que yo he escuchado de mi mamá, de mi abuelita, se dice:

La creación de los Épera fue en el río Chocó, en una playa inmensa, muy grande; no había gente, no había nada, ni comida solamente había cielo y mar y nada más, ni tierra, no era compuesta sino todo era solo selva.

Entonces ahí, el Señor Dios más poderoso ha bajado del cielo ha venido a crear a nosotros los Épera y a todas las personas que existen en este mundo, porque antes de la creación no había personas solamente había el cielo y el mar, según yo entiendo.

Había bajado Tachi Nawe, a vivir en esta playa tan solita, o sea en ese río junto al Chocó. Cuando no había nadie ella vino con su Hijito a vivir. El hijo disque preguntaba a donde va a topar a una persona, quería conversar algo, o queria hacer algo y no podía porque se encontraba solo. Al final dizque dijo, mamá yo voy a hacer un pueblo, yo voy a hacer personas, entonces disque dijo Tachi Nawe. "Mijo" ¿cómo tu vas a hacer personas? Píenselo primero cómo es que va a hacer.

Mamá, así lo voy a hacer porque yo me siento solo, yo quiero conversar con alguien, quiero hacer algo.

Entonces ya, el Diosito se puso a hacer su obra. Esta playa bonita tan inmensa que estoy mirando, esta playita yo le voy a formar un material y a media noche mi Madrecita y mi Padre tienen que darme valor para formar unas personas y eso lo haré, dijo.

Yo no le puedo ayudar, dijo Tachi Nawe, yo no puedo hacer la obra, sino usted mismo.

Entonces se fue a recoger material, para formar a las muñecas, esas muñequitas eran para volver personas, hizo muñecos de barro, muñeco de meme, muñeco de sia, muñeco de otro material más creo que ha hecho, y todo. En la playa se fue a meter a esos muñecos bien labraditos, y el iva haciendo más bonito más feito, cada muñeco. Por eso las personas no todas somos iguales, algunos somos feitos, unos más bonitos, porque el formó los muñequitos así. Bueno, el fue a meter esos muñecos, bastantes, en la playa grande, todavía existe esa playa grande. Entonces dijo, hoy día voy a formar personas en esta playa, esos muñequitos metió en la playa en la tierrita, así iba metiendo, como semillas, hembra y hombre así iba metiendo, iba metiendo toda la playa, esa playa bien grande. Entonces el le contó a su mamá que ya puso todas las semillas, y se fue a acostar, la Tachi Nawe tambièn se fue. A la media noche el se levantó, y dijo: Mi gente se está levantando y yo voy a ver.

Cuando fue a ver, dijo: mis hijos levántanse ya ustedes van a volver personas, así como yo, enseguida esa gente se levantaron alegrísimos, gritando como en fiesta, pero tan alegres todas las personas mujeres y hombres.

Entonces vino corriendo y dijo: Mamá mi obra ya está, ya se levantaron muchas gentes ahora si estoy alegre, yo ya tengo con quien conversar...

Después dijo: "está malo con un solo idioma, yo voy a tener que formar a cada cual su idioma, y empezó a decir a los gringos: ustedes van a tener su idioma, a los Épera: ustedes van a tener su propio idioma, y muchas razas de indígenas a cada cual su propio idioma, varios idiomas que nosotros no entendemos. Por eso cada uno tiene su rezo en su idioma y Tachi Aköre entiende a cada uno en su idioma”. (Lina Quiroz, 2001)

En otro relato: "el Hijo preparó tiras de chonta y de caña brava, de diferentes tamaños, y esas varas plantó en la tierra. De la chonta salieron los negros y de la caña brava los Épera, por eso son primos „meme, y no se pueden casar entre sí”. 


\section{Organización tradicional}

En las etapas de invisibilización procurada o impuesta, los pueblos tienen personajes o rituales cargados de simbolismo que dan coherencia y mantienen el tejido social identitario de los pueblos. En el pueblo Épera estos personajes que constituyen la autoridad tradicional están vinculados a los espíritus y a la sabiduría ancestral, para proteger el bienestar físico y espiritual al interior del pueblo y en las relaciones con los "vecinos" que los rodean. El Jaipana con las pildeseras o tongueras, la Tachi Nawe, los hierbateros, ejercen esas funciones fundamentales.

\section{Jaipana}

El Jaipana, es el hombre capaz de controlar a los espíritus de los tres mundos que tiene la cosmovisión Épera. Su significado es el siguiente: JAI = espíritu, sombra, alma; PA = venir arribar; $\mathrm{NA}=\mathrm{ir}^{2}$. "El jaipana es como dueño de todas las sombras, el da la orden de ir o venir... "Diosito lindo dejó ese" jai para curar no para hacer daño, ni para cobrar, ni para hacer maldad." (Lina Quiroz, 2001).

Para el pensamiento Épera, todo tiene jai, el universo animado o no: las personas Éperas o no, cualquier situación de tensión, conflicto o desorden; tienen “jai” también los rituales, las curaciones, la danza, las fiestas; la naturaleza tiene su "jai”: tierra, mar, ríos, cascadas, cerros, montes, lagunas; los fenómenos naturales: aguaceros, arco iris, rayos. Existe “jai” en todas las dimensiones del espacio y del tiempo. También en el "mundo de abajo" y sus habitantes los "tapano seres cerrados” (sin ano; Mito "Buro-poto”, Carrasco, 2010: 28) que se nutren con la fragancia de los alimentos. El “jai” puede ser armonía y sanación, pero también angustia y desequilibrio. Anima y da vida y puede causar también enfermedad y muerte. Quien controla el “jai” es el Jaipana, que generalmente es un varón, puede restablecer la armonía equilibrando las energías de las personas, del cosmos y del inframundo. Es capaz de conocer qué “jai” es el que causa daño, por su presencia o por su ausencia.

La ceremonia curativa se denomina "mesa”, es el espacio central en una habitación, en donde se coloca previamente todos los artilugios (tazas con chicha u otro licor, velas, cigarrillos, hachas de piedra antiguas, especies de bastones de madera llamados "tuma”) para el ritual que durará toda la noche. El Jaipana, sacude hojas de bijao y con cantos, rezos, silencios, convoca al "jai", a veces convoca a espíritus de jaipanas famosos ya muertos, para que juntos encuentren o armonicen el "jaura” (sombra, alma o espíritu perdido), del cuerpo del enfermo. Las palabras, los cánticos son sagrados y hacen de mediación eficaz con los “jai”. Estos cantos se pueden escuchar, en ocasiones se pueden entender, según la lengua en que se exprese el jaipana, pero su carácter de sagrados exige respeto y no se los puede repetir banalmente. Para alcanzar el trance, el jaipana recurre al consumo de plantas alucinógenas como el pildé (Yagé), o el borrachero llamado también guanto, (el agente activo es la escopolamina), estos alucinógenos requieren cuidados especiales.

"El conocimiento de Jaipana, no se alcanza por "estudios o aprendizaje”, es un don dado por Tachi Akore (Dios Padre), y generalmente se hereda, es el poder de ver más allá de la realidad, en otro nivel. Es un estado de éxtasis consciente, en el se trasciende el espacio y el tiempo. Generalmente todo asentamiento de los Épera debe tener su Jaipana”3.

2 Participantes del curso de Educación Indígena y Multicultural, Normal de La Inmaculada de Guapi, 1999

3 Leticia Pauma, Tachi Nawe de la Comunidad Sia, Curso de Educación Indígena y Multicultural, Normal de La Inmaculada de Guapi, 1999 
Generalmente los Jaipanas deben tener un ayudante, puede ser varón o mujer. Tiene la función de tomar el "pildé", para entrar en trance y ver las "sombras” o el "jai”. Se llaman tonguera o pildesera, en idioma sia "tafato".

\section{Jaipana y conocimiento}

El Jaipana es el hombre del conocimiento ancestral, es el que puede acceder al mundo oculto para los otros, no a través de estudio e investigación sino por un llamado trascendente, luego de una larga iniciación y de saberse capaz de responder a esa misión.

"El conocimiento en esta sociedad no es una producción ni construcción a nuestra manera académica occidental. El conocimiento es algo que existe, que es ubicable y consiste en "ver” algo que está "allá", en el otro nivel de la realidad. El conocimiento en la cultura Épera no se produce, se llega a él. El aprendizaje o entrenamiento para jaipana, consiste en aprender el camino para llegar a él, para poder "ver" lo que está en el otro plano de esta realidad. El entrenamiento para jaipana es un proceso para conseguir un estado de éxtasis consciente, en el cual se trasciende la corporeidad, el espacio, el tiempo, y en este estado poder establecer la comunicación con el jai, recibir la información y su participación para los efectos que se buscan” (Orozco Álvarez y Prado Paredes, 1999: 169).

\section{Tonguera o Pildesera}

“Debe ser elegido(a) por Tachi Akore, no puede ser quien quiera. Yo, intenté varias veces pero vomité todo el pildé, quedé mareado y con dolor de cabeza. Las pildeseras toman el sumo de la hierba "pildé" y caen en transe, y tienen la capacidad de ver la sombra (el jai) de las personas enfermas.

Una persona puede tener diez sombras, cae enferma cuando una o más sombras le han robado, las sombras son robadas por los antepasados, pueblos indios que tienen sus casas en lo hondo de la tierra.

La tonguera avisa al jaipana cuantas sombras faltan y en donde están. Cuando están los dos Jaipana y Tonguera, la curación es más rápida, porque es tener como la radiografía para curar... Por eso mi papá (Celso Capena) y mi mamá (Yunarda García) siempre viajan juntos”. "Aquí no tenemos el pildé propio. Hay otra planta llamada borrachera... de esta planta se sacan las hojas y se sujetan en los brazos y las piernas, y del corazón de la ramita se saca el jugo y se toma solo una cucharadita, si exageran, quedan locos y pierden el conocimiento todo el día." (Manuel Capena).

“Todo pueblo Épera debe tener su Jaipana. Aquí tenemos a Celso Capena, la pildesera es su mujer Yunarda García, sólo ve ella. Está Marcial Chirimía, ve el mismo. Porfirio Quintero, ve la esposa Ligia Gruezo. Nelson Equia, sabe ver pero no curar. Felix Chirimì ve y cura.” (Belarmino Chiripúa).

"El jaipana aprende de otros sabios, viajan donde ellos para aprender y conocer el poder de las hierbas. El mal puede ser de las personas, de la familia o de toda la comunidad o puede ser también de la tierra. Hay algunos que quieren hacerse pasar por jaipana, pero ya se los conoce que son engañadores” (Lina Quiroz).

Hay que resaltar que los jaipanas al interior de los épera, no son únicamente médicos tradicionales, son también una institución que ha permitido la cohesión y el control social entre ellos. Aunque la gran dispersión de asentamientos en Esmeraldas, ha causado que este rol tradicional de los jaipanas se ha visto también disminuido. 


\title{
Tachi Nawe
}

Llamada también "Mayorala” - Nuestra madre- el cargo es vitalicio, hereditario y debe ser “elegido" por Tachi Akore a través de sueños. Es la autoridad ética y espiritual reconocida por los Épera. Cuando el cargo ejercía un varón se lo llamaba “mayordomo”. Es el personaje, junto con el Jaipana, que da cohesión e identidad al tejido social del pueblo. Las Tachi Nawe actuales residen en Colombia.

\begin{abstract}
"Nosotros tenemos Tachi Nawe de Cristo para acá, cuando Tachi Akore (Dios Padre) y Tachi Nawe (Virgen María) ya se fueron. Cuando yo me acuerdo de este mundo, ya existió, era Idulia Dura, después el hijo Isiderio Dura, ahora están las tres hijas de Isiderio”.(Lina Quiroz).

"Yo recuerdo a Isiderio Dura, que daba consejos y nos castigaba con látigo de yaré, cuando hacíamos tonterías... El mayordomo se encontró con Tachi Akore ahí le enseñó a cantar esto y esto y esto y le quedó en la cabeza todito. Usted tiene que interesarse por todo, fue como que se murió, desde ahí quedó con poder, ese mayordomo se llamaba Alberto Chiripúa. Cuando el murió quedó la hija María Obdulia Dura, después heredó el hijo que se llamaba Isiderio Dura, cuando el iba a coger el cargo también era como que se murió, ahí volvió con el mandato. No son todos los hermanos que van a tener el cargo, es sólo el elegido. Ahora es Carmen Dura. Al hijo de Isiderio Dura le gustaba la copa, hablaba pendejadas, a ese no le tocó, el hombre tiene que ser correcto, lloraba ese hombre..." (Teófilo Quintero y Edilma Chiripúa).
\end{abstract}

“La Tachi Nawe o mayorala es una de las autoridades tradicionales del pueblo Sia líder espiritual que en los últimos años ha ido perdiendo significación, porque son pocas y no pueden visitar muchas comunidades. Además la presencia de los Cabildos, desde que existen resguardos en Colombia (Ley 89 de 1984) ha disminuido el poder de la tachi nawe” (Orozco Álvarez, 1997:8)

La Tachi Nawe ejerce sus funciones especialmente en la "Casa Grande”, ubicada en el río Saija en Santa Rosa de los Épera.

"Para los Sia todos los espacios tienen significado, pero la Casa Grande es un espacio sagrado
especial pues allí es donde el hombre y la mujer sia se forman y aprenden como vivir en comunidad,
allí el conocimiento se integra, allí se limpia, allí restablece el equilibrio, la armonía, de allí salen
las normas de comportamiento, allí se reflexionan los valores, allí se trabaja la identidad, allí se
toman decisiones, todo esto hace que sea el principa espacio de socialización en la Comunidad".
(Comunidad Éperara Siapidara de la Comunidad de Guangui en el río de Agua Clarita).

La Tachi Nawe o mayorala, tiene como funciones: dirigir las ceremonias colectivas, como los matrimonios, los bautizos, los bailes ceremoniales y las reuniones para aconsejar. Es quien transmite los mitos de origen y la historia del pueblo, debe visitar cada comunidad y enseñar el baile, el canto, el rezo. Responsable de mantener la cosmovisión, reforzando las normas internas del grupo, su identidad.

La tachi nawe tiene la posibilidad de soñar con tachinakore (nuestro padre supremo) y en esa experiencia comunicativa lograr presagios o pedir protección. Sus “consejos” fortalecen y recuperan las tradiciones. Estas “amigas” del jai mantienen la memoria mística viva, el equilibrio y armonía en su comunidad.

Los Épera de Ecuador trajeron a la Tachi Nawe para "reforzar la identidad y la cultura”. Luego de esta visita realizada a finales de 2010 e inicios del 2011, los épera han revalorizado muchas expresiones de su cultura, cuidando que no se convierta en folklor. 


\section{Cosmovisión del pueblo Épera}

La cosmovisión, da unidad, envuelve, protege, confiere sentido a todas las expresiones de la vida. Tienen razón de ser porque en los tiempos primordiales, recibieron ese don y mandato. Es el baluarte que fortalece los principios culturales, y que da energía para ser diferentes y reivindicar el derecho a esa diferencia, frente a las invisibilidades que impone el sistema de mercado, y a las uniformidades de la cosmovisión dominante en la que todo es mercancía.

En las épocas en que la invisibilidad se impone, como mecanismo de sobrevivencia, son estos mitos fundantes, los que continúan sosteniendo a los pueblos, sus identidades y sus proyectos de vida alternativos. Es la trascendencia de su origen, de su historia, vivida ya por seres míticos, que fueron capaces de superar las adversidades, (Biripoto) lo que les motiva para continuar, con la esperanza de que "otro mundo es posible". La cosmovisión del pueblo Épera fundamenta el derecho a su "territorio", que comprende no sólo la montaña, la tierra sino las honduras de la tierra y el espacio.

“Los Épera Siapidara conciben tres mundos... El primer mundo es el de arriba, en este mundo se encuentra el sol, Tachi Akore (Nuestro Dios), en la parte de debajo de este mundo se encuentran los “tápanos" (seres sin ano, mito del Biripoto). El segundo mundo es el del medio, este es Tachi Eunja, es decir nuestra tierra, en este mundo es en el que viven los Épera Siapidara, este mundo inicia en "To Khi” (cabecera de los ríos) y termina en "To Kharra” (bocanas). El tercer mundo es el de abajo, es el de los “Antau Aramoora Euka” (espacio de los tápanos). El Dios sol circula entre los tres mundos y les da luz. La Tachi Nawe (luna) es la mediadora entre los tres mundos”. (ACIESNAACIESCA-OZBESCAC, 1997).

El Pueblo Épera, es el pueblo de los ríos, desde las cabeceras, hasta las "bocanas”... Su derecho al "territorio" es trascendente, su desafío es administrar esa trascendencia, colas estipulaciones de "papeles" que exigen los Estados y que no corresponden a la racionalidad de su cosmovisión.

\section{Mito fundante del pueblo Éperara Siapidara}

El Mito es el símbolo en palabras, es el mensaje que no se agota en los términos en los que se expresan, ni en el tiempo en los que se anuncian. Palabras preñadas de contenido siempre nuevo, dan sentido a los acontecimientos, y espacio a las utopías. Los mitos, permanecen vivos, y por tanto enriquecidos, con el aporte de las generaciones y de los procesos históricos.

Por limitación de espacio, expondremos en este texto, solo un mito, que los Épera consideran importante.

\section{EL BURO-POTO (GEMELOS)}

"Antiguamente cuentan los viejos que existía un hombre al que se le empezó a hinchar el músculo inferior de la pierna, a medida que pasaban los días lo tenía más y más grande hasta que llegó el momento en que el no pudo dar paso un paso, de pronto estalló, o reventó la pierna y salió un niño, unos dicen que fueron dos los que salieron. En el momento del nacimieto fue tal el dolor que el hombre murio. Los viejos tomaron a los niños y los llamaron Buro-poto.

Uno de ellos murió, el otro al crecer preguntaba a los viejos que quien había matado a su padre, pero los viejos no le contestaban, Buro-poto se hizo mayor y seguía preguntando a los viejos por el que había matado a su padre y cada vez los viejos le contestaban diciéndole que los tigres lo habían comido. Al responder esto, los viejos tenían la intención de que Buro.Poto fuera muerto por los tigres. 
Buro-Poto al saber que habían sido los tigres, se armó de flechas y de su bodoquera y se metió en el monte con el fin de matar a todos los tigres, y así sucedió con los tigres que le saltaban al paso los mataba, hasta que quedó un solo tigre en la tierra que era una hembra preñada y esta si se pudo escapar de la venganza de Buro-Poto por eso hay tigres, sino, no existirían tigres...

Lo mismo sucedió con muchas otras fieras, como arañas, congas, osos, leones, pero con todas acababa Buro-poto.

Los viejos estaban más bravos con él, le dijeron que quien había matado a su padre había sido la sierpe que es un monstruo muy parecido al camarón pero grandísimo y habita en los pozos y come a los hombres enteros... a la sierpe también la venció con mucha sabiduría...

Finalmente acusaron a la luna. Venciendo dificultades subió hasta la luna pero solo pudo poner una mano en su rostro, por eso la luna tiene una cara oscura.

Buro-Poto todas las tardes miraba al sol, le rogó que le lleve a donde va, el sol accedió le pidió que se prepare. Al día siguiente saltó con el sol... y fueron a salir debajo de la tierra, donde había árboles muy bonitos... Cuando encontraron una casa les ofrecieron comida y el sol igual que la gente sólo olfateaban la comida, así se alimentaban, eran personas que no tenían ano y por tanto no ensuciaban. Biri-Poto comía lo que votaban y luego ensuciaba, eso no le gusto al sol ni a la gente... por eso el sol le invitó a regresar. Buro-Poto regresó a su casa, se llenó de malas costumbres, le creció el pene y perseguía a las mujeres jóvenes por la noche y las mataba, las jóvenes se estaban acabando y la gente tenía odio de Buro-Poto. Un día en que Buro-Poto estaba durmiendo cerca del fuego, las mujeres estaban cocinando bastante agua en una "múcura" grande, cuando ya estaba hirviendo el agua, una vieja le echó el agua caliente encima y Boro.Poto se convirtió en piedra bonita. Cuando los viejos vieron esa piedra bonita se pusieron a tallarla para hacer la piedra de moler maíz. Cuando iba saltando los pedacitos de piedra se iban convirtiendo en animales que chupan sangre como tábamos, mosquitos, murciélagos y otros más"4.

"Este es el cuento más bonito que tenemos los Épera. Dios hizo prueba para ver si el hombre podía tener un hijo, y le hizo preñar aquí en la pierna, pero al parir no aguantó, por eso ensayó en la mujer, parió normal. Por eso las mujeres siguen pariendo hasta el día de hoy. El muchacho que parió por la pierna murió y el hijo se llama Biripoto, es el que venció problemas, pero no supo respetar a las mujeres.... " (Belarmino Chitipúa, enero 2003).

\section{El canto y danza sagrada}

"Los viejos contaban: primero estuvo el Padre Eterno, nadie sabe cómo nació él, estaba solo, y decía: Dios mío santo ahora yo qué hago solo, voy a hacer a mi gente a mis compañeros, ahí se puso a labrar puyas, unos grandes otros pequeños de diferentes tamaños, labraba de caña brava "Sia" en lengua. Ya cuando labró todo se puso a clavar en una playa que llama "sitará", cuando estuvo clavado todo dijo: imis hijos levanten!, ahí fue que se levantó toda esa gente, y se pusieron a bailar, ahí fue que aprendimos el "karichipari", desde ahí para acá se baila, no fue inventado nada, así resultó con nosotros, nació junto con los Épera, y la danza también, no fue inventado. De ahí la gente ya quedaron bailando. Después de tiempo largo, cuando estuvo ya Jesús resultó también otras personas.

Primero fuimos los Épera, después fueron otras personas, por eso todo el territorio, el mundo entero es de nosotros, por eso caminábamos de acá por allá, no necesitábamos papel.

Nosotros estábamos un solo color. Después Diosito dijo: que tenía una piscina, dijo a todos vayan tírense al agua, entonces unos corrieron y se metieron al agua cuando estaba lleno y salieron blanquitos, después fuimos nosotros y ya no alcanzó mucho el agua por eso somos más tostaditos, cuando corrieron los últimos alcanzaron a mojarse solo los pies y las manos y esos son los negros. Ahí quedó la gente cada uno con su color, y se fueron retirando y regando así.

Después cuando hubo el diluvio, en ese tiempo, hicieron el arca. El diluvio fue porque la gente estaba como ahora, no se respetaba la raza, Diosito hizo cada uno con su raza el blanco con el blanco, el negro con el negro, el indio con su indio, según su idioma, porque cada cual tiene su 
palabra. Pero nosotros no sabemos administrar eso, queremos surtido, así como los animalitos, gallina con gallo,sin mezclar. Nosotros no queremos mezclar, porque Diosito lo prohibió, por eso no queremos, después vienen los hijos, mala raza. Todo eso prohibió Diosito. Porque estaba sucediendo eso en ese tiempo vino el diluvio."(Belarmino Chiripúa, 8 de diciembre, 2003).

Así se transmiten las normas fundamentales del Pueblo Éperara Siapidara. Y cada generación recibe estos mitos fundantes como "herencia y tarea".

\title{
Celebraciones rituales y festividades
}

Las celebraciones y festividades están estrechamente vinculadas a los mitos, en las celebraciones se recrean estos relatos sagrados y el Pueblo Épera los canta, los danza... festivamente y comparten abundante comida. "Se la llama: NEJEDEKO. La etimología de la palabra es: NE=Prefijo que acompaña a los sustantivos que designas cosas; JEDE= Compartir; $\mathrm{KO}=$ Comer" . La traducción en castellano de "comitiva", no abarca todo el sentido de la celebración.

\begin{abstract}
"Es una fiesta religiosa celebrada por los Éperara Siapidara que ayuda a mantener a la comunidad en armonía, ya que es una ceremonia que permite la reconciliación consigo mismo y con los miembros de la comunidad. Está orientada por la Tachinawe, quien vela para que se realice lo mejor posible esta ceremonia, que tiene como objetivos: mantener la armonía de la comunidad; transmitir oralmente las costumbres y tradiciones; conservar la cultura y la tradición. Durante los días que dura esta celebración, los participantes tienen espacio para: encontrarse con Dios; evaluarse personal y comunitariamente; compartir la vida (problemas, alegrías, anécdotas y también danzan cantan y alaban a Dios); se purifican realizando las celebraciones como bautizos, matrimonios, limpieza. Limpieza es sacar el espíritu malo sea de las personas como de las cosas y de lugares como los lagos, las playas, los caminos; afianzan su identidad y conocimiento de su cultura; transmiten las costumbres y tradiciones a los niños.

Esta celebración se realiza cuando la comunidad está pasando una crisis grave, de identidad, de salud, producción, enfrentamientos internos, porque no se comparte en la comunidad, se vuelven mezquinos, cuando sentimos que los espíritus malos no nos dejan hacer el bien. En estas ocasiones los mayores se acercan a la Tachi Nawe y solicitan realizar la fiesta... Es el lugar de pedir perdón $y$ volver al buen camino". ${ }^{6}$
\end{abstract}

Las fiestas fijas más importantes son: Semana Santa, San Juan 24 de junio, Santa Rosa el 30 de agosto y Navidad el 25 de diciembre. Los Épera de Ecuador, celebraron la fiesta de Navidad en 1999, "Ya son 20 años que he venido de Colombia, aquí no hemos hecho nunca las fiestas; ahora queremos ser renacientes, volver a celebrar nuestra cultura”. (Hilda y Marciano Chirimía, diciembre 1999).

Este fue un acontecimiento que marcó el proceso de los Épera en Ecuador: fue un reencuentro de todas las familias de los asentamientos, una afirmación de su identidad, rompió la invisibilidad, acrecentó la autoestima.

Cada fiesta tiene su particularidad, en torno a la fecha en que se celebra. Pero lo relevante es la tradición cultural propia como se las celebra. En Esmeraldas, hay tres momentos especiales: las oraciones; las danzas y cantos sagrados; y la comida compartida.

En Colombia en donde está la "casica” o Tachi Nawe, se dan los consejos y se celebran los rituales del matrimonio y las "limpias". "En Esmeraldas debemos tener el diálogo entre todos para arreglar problemas...” 
Las oraciones, son proclamadas en Siapedee por las mujeres mayores del pueblo, generalmente terminan con letanías o invocaciones a los santos de su devoción y a los antepasados que se los consideranj protectores del pueblo. Todos de rodillas con el rostro hacia la salida del sol ante la cruz adornada con los signos tradicionales hacen sus plegarias. Se realizan en las celebraciones y asambleas.

En las danzas sagradas, participan todos: mujeres y varones adultos, jóvenes y niños. Las mujeres ataviadas con la "paruma" (falda de color vivo, ceñida a la cintura) ,el torso desnudo, y collares de chaquira, llevan el rostro pintado. Los varones sólo con pantaloneta y la cara y el torso pintado. El canto está a cargo de las mujeres mayores, acompañan el ritmo con un tambor "tondao". Los hombres tienen también su propio instrumento que se llama "siru”, que significa instrumento traído del monte, en Ecuador este instrumento se ha perdido. Hay varias danzas y cantos: "Ome-omee paira” (danza de dos por dos), Ararirara paira (danza de ararirara), Irabai paira (danza de bajar), Karichipari paira (danza de karichipari). En la noche de Navidad se reza y baila toda la noche.

\begin{abstract}
"El mayordomo tiene un poder... cuando andaba por el monte, dos personas se paran delante de él, pensó tienen que ser ángeles mandados por Tachi Akore, desde ahí salió el canto, le enseñó a cantar, dijeron: usted va a cantar esto y esto, y todito le quedó en la cabeza. Y usted tiene que dar consejos, y usted tiene que interesarse de todo, desde ahí quedó con poder. Ese mayor se llamaba Alberto Chiripúa. De ahí para acá hay el canto, cada canto tiene su baile. Por eso nosotros decimos que el baile y el canto de nosotros son sagrados. Porque de las razas indígenas que hay en todo el mundo, lo que tienen son inventados, de nosotros no inventa más. Cuando se fueron esos ángeles, el mayordomo quedó como muerto, no podía ni hablar. Después de ese siguió su hija María Obdulia Dura, de ahí quedó su hijo Isiderio Dura, después son las tres hijas mayordomas que son: Carmen, Luz y Norberta” (Teófilo Quintero y Edilma Chiripúa, Bella Aurora, enero 2003).

“Ese cargo es por rama de las personas, no son todos los hermanos, sólo los elegidos, el que habla palabras vulgares no puede ser, en todo debe ser bien, ese es elegido”(Ibíd.).
\end{abstract}

$\mathrm{Al}$ alba comienza el reparto de la comida, primeramente a los niños, que tamborillean con la cuchara en el plato, por tres veces, como acción de gracias. Luego que han comido los niños, es el turno de los mayores. En fiestas posteriores, cada familia lleva su comida festiva, que consiste en tamales y dulces que se intercambian entre todas las familias presentes. La bebida debe ser moderada, en las grandes fiestas comunitarias no se permite el exceso de licor.

En estas fiestas, se solucionan problemas y dificultades que afectan al pueblo, consolida las relaciones entre las familias, el pueblo se siente purificado. El riesgo de los pueblos es folklorizar lo que es sagrado, convirtiéndolo en espectáculo fuera del tiempo y de los lugares propicios; las celebraciones se vacían del contenido profundo que tiene en las culturas de los pueblos.

\title{
Ritos de transición
}

Actualmente en Esmeraldas, para la unión de las parejas, se ponen de acuerdo las dos familias, y generalmente los mayores dan consejos a los novios.

En muchas ocasiones la pareja se va a trabajar fuera para tener algún recurso. Después de un tiempo regresan y son recibidos en la casa de los padres de la novia. "Cuando tienen hijitos construyen su propia vivienda”. Los partos son atendidos por el esposo y la mamá o la suegra, quien esté cercana. A la mujer se le cuida 20 días, se le debe bañar con agua caliente con hierbas. Si se baña con agua fría le puede causar "pasmo". Al niño se le corta el cordón umbilical "con machete viejo, no muy afilado, para que no aprenda a coger armas". 
A los difuntos se les celebra la última noche, nueve días después de la muerte, es la "última despedida para que queden tranquilos". El cementerio debe ser un lugar fuera del pueblo, "para que no molesten". En Esmeraldas los ritos tradicionales de pasaje ya no se practican.

Con esta rica herencia cultural y espiritual llegan los Épera a Ecuador. Es lo que los mantuvo con su identidad a pesar de las adversidades y las invisibilidades.

\section{Organización política}

La organización política en un pueblo triplemente “invisibilizado”, -invisibilización procurada, invisibilización impuesta e invisibilización generada- (Carrasco, 2010: 87) disperso y con dificultades para la comunicación es prácticamente imposible. El proceso que ha debido realizar el pueblo Épera, en este aspecto, ha sido esforzado. Son los "jaipana” o médicos tradicionales quienes han ejercido el rol de "autoridad" que ha permitido la cohesión y regulación en los asentamientos de las familias ampliadas.

Cuando la organización socio-política avanza, los roles de las autoridades tradicionales son relegados. Los Jaipana se concentran en el mundo de los “jai” (espíritus), y no tienen un rol en las asambleas comunitarias ni en las festividades "nejedeko” del pueblo.

En el proceso organizativo de Colombia, sucede el mismo fenómeno. La Tachinawe pierde la importancia tradicional de control social de su pueblo y los cabildos como autoridades de las comunidades indígenas es una institución impuesta.

\footnotetext{
“En las comunidades Éperara se conforman a partir de 1984, desde su creación los cabildos han luchado por la titulación de resguardos y la defensa de los recursos naturales, por otra parte han tenido relación con diferentes instituciones del Estado para buscar proyectos y programas en beneficio de las comunidades... Los cabildos en su inicio chocaron con las autoridades tradicionales del pueblo sia, ya que estos pretendían desconocer la autoridad de la tachi nawe y Tachi Akore...

En la actualidad en las treinta y dos comunidades sia existen cabildos locales, siendo su organización muy débil... Posteriormente crearon el Cabildo Mayor con representantes de las comunidades principales (1994). Luego de varios intentos organizativos en 1995 se creó la Asociación de cabildos indígenas Éperara Siapidara de Nariño (ACIESNA), en 1996 se creó la Asociación de Cabildos Indígenas Éperara Siapidara del Cauca (ACIESCA), pocos meses después hay una división y aparece otra asociación OZBESCAC.

La unión de estas tres asociaciones conforman la Organización Regional Indígena Esperara Siapidara” (ACIESNA-ACIESCA-OZBESCAC, 1997).
}

Esta cita del documento de la organización del Pueblo Éperara Siapidara en Colombia, tiene importancia para que el Pueblo Épera del Ecuador, conozca el proceso de sus "familias" originarias.

\section{Organización política en Ecuador}

Las autoridades, que deben regir en el nuevo modelo, responde a otra realidad sociopolítica, por las exigencias que conllevan, deben “ser estudiados”, en la situación de los Épera solo pueden ser los jóvenes que tuvieron la posibilidad de asistir a escuela y colegio. El número es reducido, el "poder" se concentra en pocas familias ampliadas y en pocos miembros del pueblo. El "poder" tradicional es relegado, la autoridad de los “ancianos" se ve disminuida, y los jóvenes que deben asumir la dirigencia dependen del respaldo de la asamblea para poder tomar decisiones, es decir depende del número y la fuerza de la familia ampliada a la que se pertenecen. Este es otro elemento de vulnerabilidad para los pueblos en estas situaciones. 
La mayoría de la población Épera, residente en Ecuador, no tenía cédula de identidad, esta era otra variable que generaba la invisibilización. Los trámites para alcanzar brigadas de cedulación fueron urgentes y en el proceso hubo dificultades.

En Ecuador la interrelación con la nacionalidad Chachi que ya pertenecía a la CONAIE, les llevó a algunos compañeros Épera a contactarse con esta organización. En 1999 en una reunión los Épera nombran al presidente (Jorge Chitipúa) que luego participa en una Asamblea de la CONAICE (Confederación de Organizaciones Indígenas de la Costa Ecuatoriana).

La CONAIE, asume la responsabilidad de dar asesoría a los Épera, para que avancen en la cohesión y estructuración de su organización política, con este fin envía al compañero Aníbal Chávez (26 febrero 2000). El Pueblo Épera debe pasar de la dispersión e invisibilización a una organización sociopolítica centralizada.

La Organización de la Nacionalidad Épera del Ecuador (ONAEE), se legalizó con acuerdo ministerial No 001069 del 12 de septiembre del 2001. La organización es filial de la Regional de la Costa: CONAICE (Organización de las Nacionalidades Indígenas de la Costa Ecuatoriana) perteneciente a la CONAIE (Confederación de las Nacionalidades Indígenas del Ecuador).

En un taller, como signo de apropiación, buscan nombres ancestrales para referirse a los miembros de la directiva de la organización sociopolítica naciente:

TACHIPORO (nuestra cabeza) = presidente.

CHARRÂRÂ = alguacil, vocales.

ENJAAKÎPARI JÔMARADÊ = vigilante del territorio de la Comunidad (vocal del Territorio).

TACHIPEDEE WÎPARI = el que castiga en nuestra lengua (vocal de Cultura y Justicia).

KÎNICIA = Lo que pensamos (vocal de Organización y Política).

PARATA WARIPIDAITEE = nuestro dinero va a crecer (vocal de economía)

KAWAIDEE OKAWABI = aprender lo que deben hacer (vocal de Educación).

KAPIABI = está alentado, con salud (vocal de Salud y Vida)

EUJANÎIEBI = aire, tierra, no contaminados (vocal de Medio Ambiente).

El proceso de organización política del pueblo Épera les exigió pasar aceleradamente, de una autoridad simbólica, el Jaipana, ejercida en los asentamientos dispersos. A una autoridad centralizada, que tiene otros códigos referenciales. Además de este cambio organizativo interno, debían responder a los desafíos que enfrentaba la Organización Indígena nacional, (CONAIE) frente a los gobiernos de turno de la época. Así debieron participar en los levantamientos, salir de sus “tambos”, de la invisibilidad, viajar a Quito, la mayoría por primera vez, y sentir que los pueblos indios eran diversos y que tenían fuerza (1febrero, 2001). En su caminar, estos acontecimiento son marcantes. Experimentan que son muchos, que tienen fuerza y que su voz y sus acciones son escuchadas.

\section{Territorio, fundamento de la visibilidad}

En todas las reuniones, el pueblo Épera de los asentamientos de Esmeraldas, expresaba la añoranza, la urgencia, de un territorio, que los recoja y acoja, y que les de posibilidad de ser realmente pueblo.

El presidente de los Épera (10 de noviembre de 1999) en la Asamblea expresó el sentir de su pueblo “Somos como pájaros sin nido”. El Territorio se empezó a soñar como espacio común, indispensable para la autosubsistencia, vivencia de su cultura, refuerzo de su identidad.

Para los Épera Siapidara, el territorio es parte de su cosmovisión, es un ser vivo, que permanece en el tiempo. Es “Tachi Eunja” Nuestra Tierra, es el lugar en donde Dios se manifiesta diáfanamente. 
"Madre naturaleza que da vida y alimento, da albergue, es espacio de recuperación, el territorio es el lugar en el que moran los espíritus que nos guían y nos dan la sabiduría y el conocimiento". El territorio es parte de su cosmovisión, integra los tres mundos, el de lo alto el de las profundidades y el que vivimos"'.

La urgencia de territorio para los Épera era evidente. Un desafío impostergable, un clamor en todas las reuniones, expresado tanto en los espacios celebrativos, en sus cantos y danzas, como en las intervenciones en las Asambleas de la naciente organización. Por esto en la primera celebración ancestral de todos los asentamientos del Pueblo Épera (diciembre, 2000), el compromiso fue luchar por el territorio y declarar el año 2000, como año del territorio de los Épera.

Así empezó un largo peregrinar. Se elabora el proyecto del territorio. Se envían a las instancias nacionales (CONAIE, PRODEPINE, CODENPE) a ONG's. y amigos del exterior. Simultáneamente se inicia el proceso de verbalizar el "sueño del territorio Épera": forma de posesión: familia nuclear o familia ampliada; posible extensión de las fincas; producción básica; centro poblado; espacios comunitarios... Se delineaba el "Reglamento del territorio":

"El territorio es para todos los Épera que tengan residencia fija en el país. Si alguien se va no puede vender, ni prestar, ni dejar de herencia. La tierra vuelve al pueblo, cada uno tiene posesión indefinida, mientras viva en este lugar.

De los proyectos productivos tienen derecho quienes participan en las mingas y asisten a las asambleas regularmente.

La "finca" será de la familia, si el hombre o la mujer se separan la finca es de quien se quede con los hijos.

Las fincas de la familia ampliada serán colindantes.

Producir productos de corto plazo para la subsistencia y de largo plazo para asegurar ingresos y mejorar la vida.

Establecer un área comunitaria, que debe ser sagrada, para la casería, no se puede cortar árboles.

Para cortar un árbol se necesita permiso de la asamblea. Por un árbol cortado se deben sembrar tres arboles nativos.

Formar un pueblito con las casas de todos los Épera. Vivir cuidándonos unos a otros. Debemos tener una escuela para que aprendan los niños que están renaciendo, debemos tener un nocturno para aprender los viejos. Debe haber una Iglesia.

Debemos tener personería jurídica como ONAEE (Organización de la Nacionalidad Épera de Ecuador).

La tierra que se adquiera para el pueblo Épera, se realizará por escrituras a favor del Vicariato de Esmeraldas, hasta que los Épera tengan personería jurídica”.

Se propone al Sr. Obispo esta decisión de la Asamblea (13 de agosto, 2000), el que acepta, ofreciendo también su colaboración económica.

En una de las Asambleas eligen como responsable del territorio a Gabriel Tascón y comisiones que saldrá por turnos. El rol que tienen es importante, deben verificar que las fincas que se decidan comprar no estén ocupados por otros campesinos, y comprobar que las hectáreas ofrecidas en el convenio sean reales.

En todas las asambleas había un punto para „soñar en el territorio y comunitariamente apropiarse ideológica y espiritualmente del mismo.

7 Participantes del Curso de Educación Indígena y Multicultural, Monografía, Normal de la Inmaculada, Guapi, 1999 


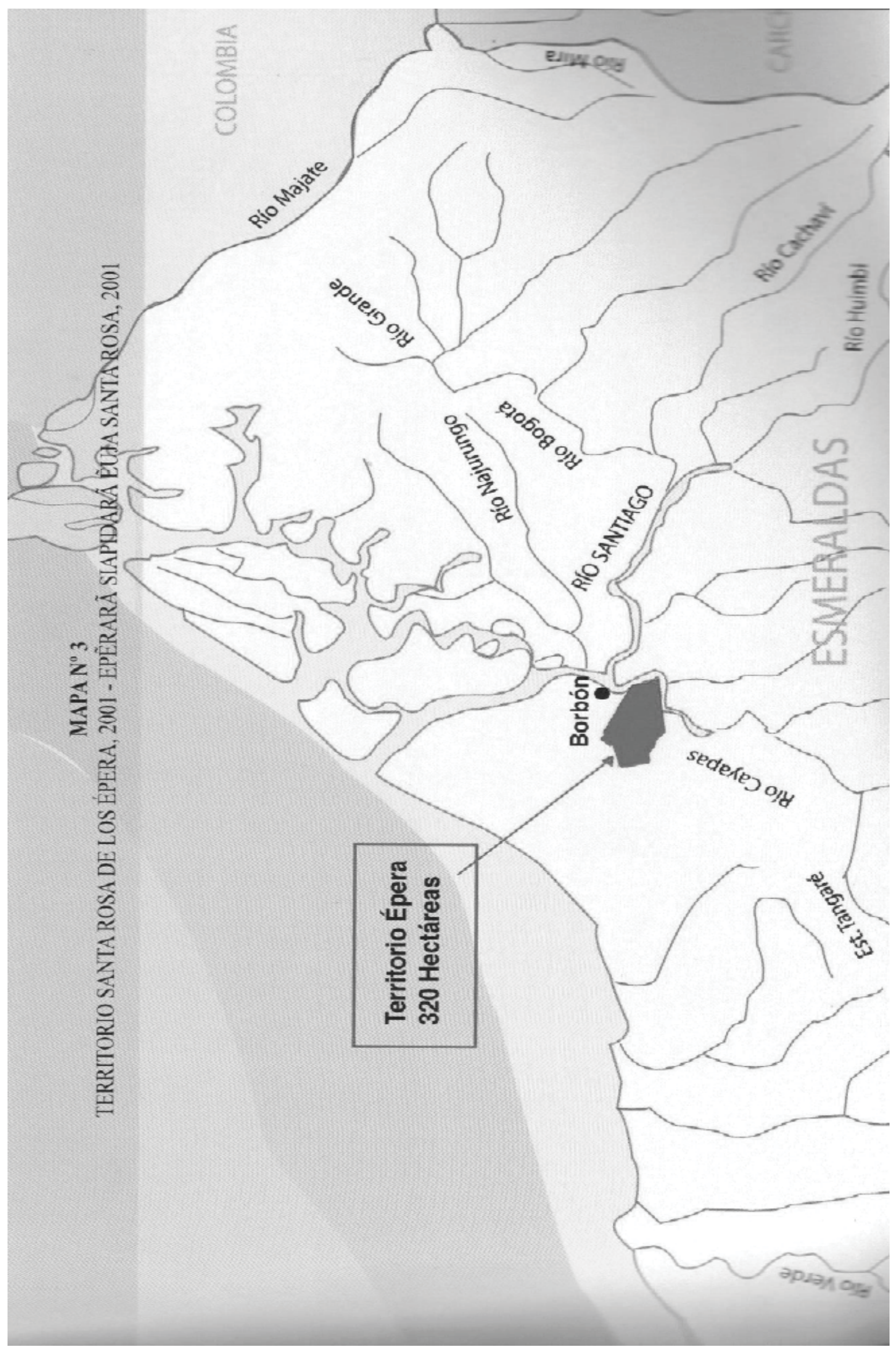




\section{Proceso de búsqueda del territorio}

Las fincas que se adquieran debían responder a la realidad socio-cultural del pueblo Épera. Los asentamientos en Colombia, son a la vera de los ríos, hace décadas tenían sus tambos dispersos. Posteriormente con la decisión del Estado Colombiano de territorializar a los pueblos Indígenas, en los llamados “resguardos”, y la situación de violencia creciente, obligó a nucleisar los asentamientos por familias ampliadas. Este era un referente para el territorio de los Épera en Ecuador.

Se inicia la búsqueda del territorio, proceso largo, no exento de tensiones, y dificultades internas y externas. Ninguna finca de la zona tenía escrituras notariadas, sólo tenían un documento del ex IERAC, actual INDA (Instituto Nacional de Desarrollo Agrario) de "derecho posesorio" de la finca. Primero se debía legalizar la propiedad realizando escrituras de cada una de las fincas para poder adquirirlas. Las fincas debían ser colindantes, formando un "cuerpo cierto”. En el proceso de adquisición de fincas, hubo un alza desmedida de precios, por la migración de colombianos y por la ampliación de la frontera agrícola, especialmente el cultivo intensivo de palma africana.

En el país no había ninguna posibilidad de encontrar financiación para adquirir territorio. En la zona de Esmeraldas no existen tierras del Estado, todas tienen propietarios generalmente posesionarios de la tierra con anuencia del IERAC, y sin escrituras notariadas.

\section{Fincas para familias ampliadas}

La esperanza y los sueños se concretaban con apoyos de amigos de fuera del país. La comunicación del primer apoyo para la adquisición del territorio (27 mayo 2000) se recibió, vía telefónica. La Congregación de las hermanas de la Providencia de Bélgica ${ }^{8}$, dona todas las jubilaciones recibidas por las hermanas en ese año, para el territorio: un millón de francos belgas. Se adquirieron 347 hectáreas.

Inmediatamente se inician trámites para la adquisición de la primera finca. La fiesta de posesión de “Tachi eunja” (nuestra tierra) fue el 16 de septiembre del 2000. Ritual ancestral de apropiación, danza, comida, oraciones, símbolos de identidad, con alegría desbordante. La invisibilidad procurada era vencida. El Enjaakipari jomaradë (vocal del territorio) Gabriel Tascón, en mingas construyó su cabaña y se quedó a cuidar la tierra. El territorio queda a $15 \mathrm{~km}$. de Borbon, río arriba. Posteriormente llegan otros aportes y se negocian otras fincas ribereñas al rio Cayapa.

Con el apoyo de un técnico del INDA (Instituto Nacional de Desarrollo Agrario) el 14 de enero 2002, en mingas, se inicia la apertura de “mangas” (límites) de las fincas con sus vecinos.

El proceso continúa entre danzas, cánticos, y asambleas a veces tensas. (marzo, 2001) se decide que las “fincas” por familia nuclear sea de 3.5 hectáreas. A las(os) jóvenes solteros mayores de 15 años se les asigne una hectárea. Los lotes de las familias que conforman una familia ampliada deben formar un "cuerpo cierto”. El tamaño de la finca dependerá del número de familias nucleares y de hijas(os) mayores de 15 años que tenga una familia ampliada. Se decide dejar para Territorio Comunitario 70.05 hectáreas, ubicadas al fondo del territorio junto a la laguna, a la que empiezan a considerar "sagrada". Se reserva espacio para el centro poblado, a la vera del río.

8 Otras instituciones que apoyaron para la adquisición del territorio de los Épera fueron: Fundación Wilhem Oberle Stiftung; Missio Viena;Vicariato Apostólico de Esmeraldas (Cfr. Carrasco, 2010: 78). 
En este proceso se debe cuidar la unidad de la familia ampliada o extensa. La "finca” debía responder al modelo de asentamiento tradicional del pueblo Épera. "Los lazos de la sangre entre las generaciones son más importantes que los lazos de matrimonio” (NANDA, 1994: 222). Esta afirmación es mayor en el Pueblo Épera que ha debido pasar por múltiples vicisitudes.

Los trámites para la legalización de la Organización de la Nacionalidad Épera del Ecuador (ONAEE) y de la directiva son ágilmente realizados, con el apoyo del delegado de la CONAIE para este fin, el compañero amazónico Aníbal Chávez.

El 23 de febrero del 2003, en “Comitiva” (fiesta con daza, cantos, rezos y comida compartida) y asamblea especial se entregan las escrituras, debidamente notariadas, al pueblo Épera en manos del presidente Salvador Chirimía. En las escrituras, hay una cláusula, decidida en varias asambleas del pueblo Épera que estipula: "La propiedad del territorio es del Pueblo Épera, ninguna familia puede ejercer ningún acto de propiedad sobre la tierra. Las familias son posesionarias del lote, correspondiéndoles el uso y usufructo. Si alguna familia sale del Ecuador, el lote vuelve a ser comunitario”. Las familias van construyendo sus viviendas en el pueblo. La visibilidad es signo del proceso de la recuperación de la identidad y cultura.

Las familias Épera crecen, las 347 hectáreas de territorio son insuficientes. La ONAEE, continúa buscando tierra para que acoja a su pueblo. En mayo del 2011 hay avances significativos, con el apoyo de GTZ - FOCIN, (Cooperación Alemana al Desarrollo) el presidente de la ONAEE, Salvador Chirimía, inicia los trámites para adquirir 90 hectáreas para ampliar el territorio del pueblo Épera. Además tienen la oferta de apoyo de la ONG. W, Oberle Stiftung de un aporte para ampliar el territorio. La urgencia es el avance del cultivo de palma africana en la zona, que encarece cada vez más la tierra y extiende la frontera agrícola.

\section{Producción agrícola}

La adquisición de la tierra para el pueblo Épera, conlleva la urgencia de la producción de la misma, para la subsistencia. El PRODEPINE (Proyecto de Desarrollo para los Pueblos Indígenas y Afroecuatorianos) aprueba el proyecto productivo (mayo 2002) de \$42.000.00, que entregará en dos cuotas. Está destinado a la producción de coco y plátano. Con asesoría de técnicos de la entidad, y asumiendo la sabiduría ancestral se realiza el proyecto en cada una de las fincas de las familias nucleares.

Este primer proyecto contribuyó no sólo en el aspecto productivo, sino en la apropiación real de la tierra, en la consolidación de la organización, y en el fortalecimiento de su identidad.

Posteriormente, con apoyo de otras entidades se continúo con cultivos de arroz, maíz, frejol, yuca, málaga, caña de azúcar, con la técnica tradicional de "roza y barbecho”.

La familia como unidad productiva, tiene definidos las tareas por sexo y edad. Varones adultos: construyen la cabaña; cuidan la finca: deshierbe, limpia y tumba; reman en viajes largos, son motoristas. Los niños: acarrean agua a la cabaña y ayudan a su padre. Las mujeres adultas: preparan los alimentos, lavan la ropa, ayudan a la siembra del plátano, trabajan artesanía, cuidan a los niños, limpian la casa, crían y cuidan los animales domésticos.

Las niñas: cuidan a sus hermanos pequeños, ayudan a lavar la ropa, y ayudan a su madre en todas las tareas. 


\section{Artesanía}

La mayoría de mujeres Épera son hábiles tejedoras de canastas, que trabajan en sus propias cabañas; antiguamente tenían solo fines domésticos, en ellas se guardaba la ropa y otros enseres de la casa.

La materia prima son fibras y bejucos de la zona, que son tratados con hierbas especiales para darles las diversas tonalidades del “rojo y del negro”. Trabajan con chocolatillo, piquihua, yaré, rampira, tetera; hay gran capacidad de adaptación y domesticación de nuevas fibras y bejucos. Estas ramas, se les somete a un tratamiento de descortezado y partido en tiras longitudinales.

El chocolatillo una fibra que solo crece en los humedales, ecosistema que va desapareciendo por la tala indiscriminada de los bosques, para que sea durable se debe cortar en luna menguante. Actualmente las mujeres deben comprar esta fibra.

Con apoyo de la FAOEC (2010), las mujeres han consolidado la producción de las fibras que constituyen la materia prima para la elaboración de su producción y han tenido acceso a mercados a través de la participación en ferias artesanales.

En este tejido de aliados que apoyan para que el pueblo Épera afiance su camino hay proyectos que pueden afectar seriamente el medio ambiente y la salud del mismo pueblo, uno de estos es la “crianza de chanchos", en un ecosistema frágil, en donde no existe agua potable, esta iniciativa ciertamente constituye un riesgo y es cuestionable.

\section{Afranzando la vida: educación y salud}

La tasa de analfabetismo en el pueblo Épera en 1999 era del 30\% en personas mayores de 8 años. El problema tiende a agravarse por el alto porcentaje de niños que no acuden a la escuela, por las distancias y por la situación de extrema precariedad que viven en los asentamientos. En todo el pueblo Épera hay dos bachilleres y un joven en $5^{\circ}$ curso de secundaria. Estos tres jóvenes se preparan en los elementos de pedagogía para asumir la tarea de profesores de la futura escuelita del pueblo. Se iniciaron los trámites en la Dirección de Educación Bilingüe de Esmeraldas, para obtener bonificaciones y la apertura "legal" de la escuela. Con trámites engorrosos se alcanzó dos bonificaciones.

La vida se afianza. La estructura prefabricada de la escuela para el pueblo Épera es transportada desde Esmeraldas a Borbón y por lancha hasta Santa Rosa de los Épera (abril, 2002). Una minga esforzada. La escuela es donada por el Vicariato de Esmeraldas, una estructura prefabricada de madera y caña de 16 x 6.5 m. La escuela se llama “EPERÂRÂ SIA PIDÂRÂDE”.

En los adultos hay el 95\% de analfabetismo. En asamblea decidieron solicitar al Vicariato la extención educativa primaria a distancia "Monseñor Leonidas Proaño", que funcionará en Santa Rosa de los Épera. Se inicio en mayo del 2004, bajo la tutoría de Manuel Capena y Wilson Chiripúa.

Estos acontecimientos continúan fortaleciendo la identidad, la autoestima del pueblo Épera. Dar respuesta a tantos desafíos continuos es difícil, la escuelita fue una exigencia que requirió tiempo para ser incorporada a la vida de las familias; los niños ayudaban en los trabajos de la casa y de las nacientes fincas, las faltas eran frecuentes; los jóvenes profesores no tenían toda la capacitación pedagógica para cumplir su misión. Con dificultades "Eperâra Sia Pidârâde" sigue adelante.

En julio del 2011 se graduaran los dos primeros licenciados en pedagogía; y en la extensión de San Lorenzo de la Universidad Católica de Esmeraldas, estudian 4 jóvenes épera. Actualmente, el pueblo ha iniciado un proceso importantísimo de recuperación del Siapedee, con la asesoría de un profesional lingüista (Cfr. Gómez Rendón, 2005). 
El equipo de salud del Vicariato CECOMET compuesto por profesionales, hace recorridos periódicos por los ríos de la zona. Santa Rosa de los Épera empezó a ser atendida regularmente, trabajando conjuntamente con la delegada de salud del pueblo Épera Lina Quiroz.

Los pasos dados son avances irreversibles; el sendero de las invisibilidades a la visibilidad fue y sigue siendo un desafío cotidiano que exige respuestas sabias y comunitarias desde las raíces de la cultura e identidad del pueblo Épera.

\section{Proceso de visibilidad}

En la etnografía “Los Épera Siapidara en Ecuador” (Carrasco, 2010: 87) se tomaba como herramienta de análisis las “invisibilidades” tejidas en torno a los Épera: la invisibilidad procurada, la invisibilidad impuesta y la invisibilidad generada por el sistema neoliberal globalizados.

Se puede afirmar que el pueblo Épera está en un proceso de superación de estas invisibilidades que constituían una amenaza que podía conducir al etnocidio y al genocidio.

El acelerado proceso de organización, el territorio adquirido y en posible expansión, las redes de aliados solidarios que apoyan los procesos productivos, de salud y de educación, son los que contribuyen decididamente para que el pueblo Épera venza las décadas de invisibilidad y su vida con todo el rico bagaje cultural tengan viabilidad y sostenibilidad.

\section{Bibliografía}

ACIESNA - ACIESCA - OZBESCAC ${ }^{9}$, El Pueblo Éperara Siapidara, la construcción colectiva de nuestro plan de desarrollo, noviembre de 1977, Mimeografiado.

Barret S., A. 1984. Los indios cayapas del Ecuador, Quito, Ediciones Abya-Yala.

Carrasco A., Eulalia. 2010. Los Éperara Siapidara en Ecuador, de la invisibilidad a la visibilidad, Quito, Tramaediciones.

Gómez R., Jorge (Ed.) 2005. Rescate de la lengua Siapedee en Ecuador, Copia, Borrador de Trabajo.

Nanda, Serena. 1994. Antropología Cultural. Adaptaciones socioculturales, Quito, Instituto de Antropología Aplicada.

Orozco A., Marisol y Prado P., Nelly. 1999. La escritura y lo sagrado entre los Épera Sia Pidara, En: Aguirre L., Daniel (Coomp.) Culturas, lenguas, educación, Bogotá, Fondo de Publicaciones Universidad del Atlántico. pp. 165-170.

Otero, Jesús. 1952. Etnología caucana, los indios cholos. Popayán. Ed. Universidad del Cauca. pp. 107-144.

9 ACIESNA (Asociación de Cabildos Indígenas Éperara Siapidara de Nariño), ACIESCA (Asociación de Cabildos Indígenas Éperara Siapidara del Cauca), OZBESCAC, (Organización Regional Indígena Éperara Siapidara), El pueblo Éperara Siapidara”, Copia, 1997. 


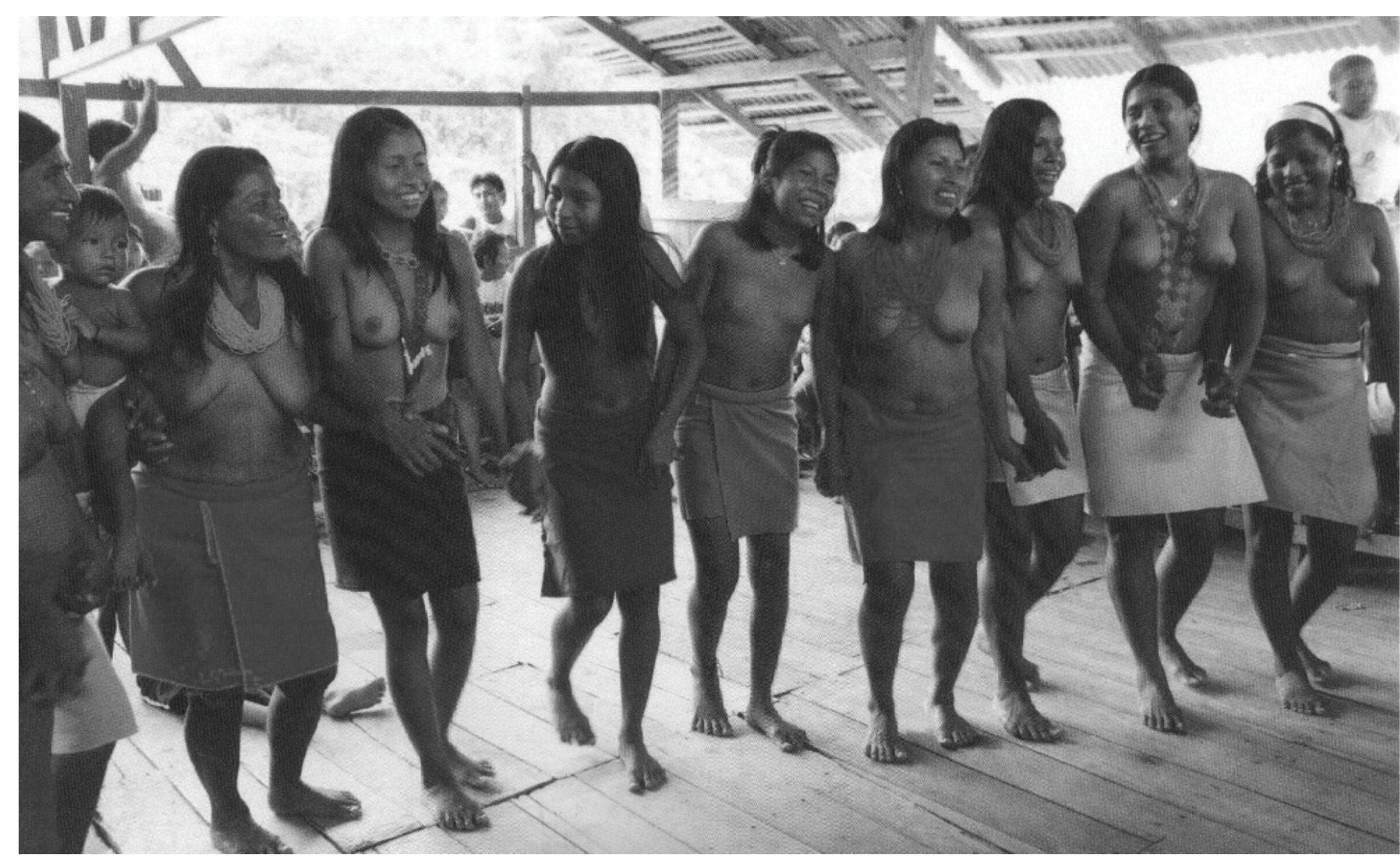

En las danzas sagradas de los Épera participan todos. Las mujeres se pintan el rostro y utilizan collares de chaquira y faldas de colores vivos. Foto tomada del libro de Eulalia Carrasco, "Los Siapidara en Ecuador. De la invisibilidad a la visibilidad”, 2010. 
El pueblo de los Épera es el pueblo de los ríos. Foto tomada del libro de Eulalia Carrasco, "Los Siapidara en Ecuador. De la invisibilidad a la visibilidad”, 2010.

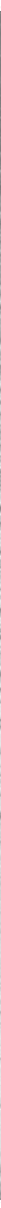

